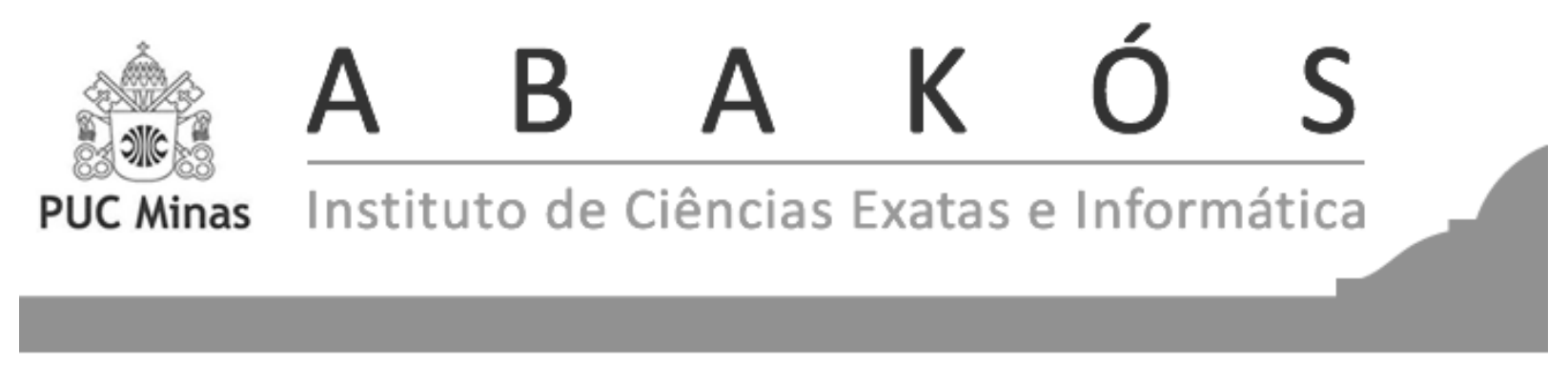

\title{
O uso das Tecnologias da Informação e Comunicação no ensino de Cálculo Diferencial e Integral: reflexões a partir de uma metanálise*
}

The use of Information and Communication Technologies in the teaching of Differential and Integral Calculus: reflexions from a meta-analysis

\author{
Jeronimo Becker Flores ${ }^{1}$ \\ Valderez Marina do Rosário Lima ${ }^{2}$ \\ Thaísa Jacintho Müller ${ }^{3}$
}

\begin{abstract}
Resumo
Neste trabalho, é apresentado um fragmento de uma pesquisa maior cujo objetivo é compreender como vem ocorrendo o uso das tecnologias digitais no ensino de Cálculo, e quais seus impactos nas práticas pedagógicas. Como método de pesquisa, escolheu-se a metanálise, pois se desejava partir de pesquisas já realizadas para chegar a um entendimento do fenômeno investigado. Assim, foram analisados artigos publicados em periódicos nos últimos dez anos. No processo interpretativo e descritivo, emergiram três categorias: (i) recursos de apoio, em que são considerados distintos recursos tecnológicos digitais. (ii) software, em que são consideradas as implicações dos programas no ensino e na aprendizagem. (iii) ensino e tecnologia, em que aborda-se a relação entre os dois aspectos. Os dados obtidos permitem dizer que a inclusão de tecnologias digitais no ensino de Cálculo não é tarefa simples, e que é necessário maior investimento na formação dos professores para que isto ocorra. Por ora, podemos considerar que ainda é necessário avançar em relação às pesquisas sobre o ensino de Cálculo no contexto das tecnologias digitais.
\end{abstract}

Palavras-chave: Cálculo diferencial e integral. Tecnologias de informação e comunicação. Ensino.

\footnotetext{
${ }^{*}$ Submetido em 08/07/2017 - Aceito em 26/02/2018

${ }^{1}$ Mestre em Educação pela UCS. Licenciado em Matemática pela UCS, Brasil- jeronimobecker@gmail.com ${ }^{2}$ Doutora e mestre em Educação pela PUC RS. Licenciada em Biologia, Brasil- valderez.lima@pucrs.br

${ }^{3}$ Doutora em Informática na Educação pela UFRGS. Mestre em Matemática pela UFRGS. Graduada em Matemática pela PUC RS, Brasil- thaisa.muller@ pucrs.br
} 


\begin{abstract}
In this paper, it is presented a fragment of a larger research, which describes the use of digital technologies in the teaching of Calculus and its impact on developed pedagogical practices. The chosen research method was the meta-analysis, in order to work with finished researches to reach an understanding of the investigated phenomenon. Thus, articles published in journals in the last ten years were analyzed. In the interpretative and descriptive processes, three categories were revealed: (i) support resources In which different digital technological resources are considered. (ii) software, in which the implications of the programs in teaching and learning are considered. (iii) teaching and technology, in which the relationship between the two aspects are discussed. From the data gathered it was shown that the inclusion of digital technologies in education is not a simple task, and it is necessary to invest in training to encourage the teachers to include technological resources in their practices. For the time being, we may consider that it is still necessary to move forward with research on calculus teaching in the context of digital technologies.
\end{abstract}

Keywords: Differential and Integral Calculus, Information and Communication Technologies, Teaching. 


\section{INTRODUÇÃO}

Na prática docente, como professores de Cálculo diferencial e integral, os dois primeiros autores deste trabalho têm observado as dificuldades dos estudantes na disciplina e constatado que elas possuem diferentes causas. Lacunas em conteúdos de matemática básica, dificuldades em representações geométricas e algébricas e em procedimentos operatórios, por exemplo, têm levado à reprovação e evasão. As vivências e pesquisas de ambos os autores, relatadas em Müller (2015) e em Flores (2013), dentre outros trabalhos, indicam que as tecnologias digitais aliadas à prática pedagógica podem se constituir em recursos para a superação das dificuldades, ampliando as condições de sucesso dos estudantes. Aliado a isso, os responsáveis por este texto estão envolvidos em uma pesquisa que procura compreensões relacionadas ao ensino de Cálculo (MÜLLER, 2015) (FLORES, 2013).

Esse contexto levou ao interesse e também à necessidade de compreender o atual status da produção científica nacional no que se refere à utilização de tecnologias digitais no ensino de Cálculo, uma vez que a temática permeia o contexto da investigação que vem sendo desenvolvida pelos autores deste texto. Para isso, realizou-se uma pesquisa bibliográfica do tipo metanálise, que compreende levantamento de obras, organização e compreensão de novos alcances a partir das pesquisas consideradas (BICUDO, 2014). Assim, buscou-se compreender o ponto de vista apresentado por distintos autores em relação ao tema, considerando similaridades, distinções, convergências e divergências.

O panorama apresentado neste trabalho é uma das múltiplas faces relativa ao ensino de Cálculo, e entende-se ser necessário ampliar a discussão, aprofundando outros aspectos que já foram discutidos por outros autores, como por exemplo, culturais e epistemológicos (OLIVEIRA; RAAD, 2012) e pedagógicos (CABRAL, 2015). Esses e outros pesquisadores situam o panorama do ensino de Cálculo como algo complexo, que precisa ser analisado a partir de múltiplas frentes. A especificidade aqui discutida pretende situar a atual produção teórica em relação às tecnologias digitais e ao ensino de Cálculo, apresentando novos entendimentos a partir do que já foi publicado.

Para compreender a atual conjuntura da produção acadêmica em relação às tecnologias digitais no Ensino de Cálculo, optou-se pela efetivação de uma metanálise, em acordo com as propostas teóricas de Bicudo (2014). Esse processo foi norteado pelo seguinte problema de pesquisa: como se dá o uso das tecnologias digitais no ensino de Cálculo diferencial e integral? (BICUDO, 2014)

Nesse trabalho, objetivamos compreender o panorama contemporâneo de uma faceta relacionada ao ensino de Cálculo. Assim, o estudo se justifica pela relevância científica, na medida em que poderá orientar ou mesmo fornecer um ponto de partida para estudos posteriores.

Desse modo, o texto que segue está organizado em quatro seções além da própria introdução: fundamentação teórica, procedimentos utilizados, apresentação e análise dos dados de pesquisa e considerações finais. 


\section{FUNDAMENTAÇÃO TEÓRICA}

Nesta seção apresentam-se os norteadores teóricos que fornecem a base para a realização desta pesquisa. Eles são os pontos de partida para a análise e interpretação dos dados. Inicialmente, consideram-se as tecnologias digitais na Educação para, na sequência, serem considerados seus impactos no ensino de Cálculo.

\subsection{Tecnologias digitais na Educação}

Atualmente, as tecnologias digitais fazem-se presentes nas mais distintas esferas da sociedade, seja na organização e na sistematização de informações, seja no comércio eletrônico, nas formas instantâneas de se comunicar e de se relacionar, entre outras. As tecnologias digitais parecem fazer parte da atual conjuntura de mundo, sendo fatores de impacto na própria cultura vigente. Para Lemos, está-se vivendo um momento de cultura digital, definido como:

Um ecossistema complexo onde reina a interdependência entre o macro-sistema tecnológico (a rede de máquinas interligadas) e o micro-sistema social (a dinâmica dos usuários), construindo-se pela disseminação de informação, pelo fluxo de dados e pelas relações sociais aí criadas (LEMOS, 2002).

Essa cultura pressupõe relações distintas entre os sujeitos e entre os sujeitos e as informações, as quais circulam de maneira mais democrática e dinâmica. Nesse contexto, o homem influencia a tecnologia e a tecnologia influencia o homem em uma relação mútua e integrada.

A Educação não ficou imune a essas influências, uma vez que é composta por sujeitos oriundos de uma sociedade caracterizada pela cultura digital. Esse fato tem levado distintos pesquisadores a preconizar, há tempos, a utilização das tecnologias digitais como fator catalisador de mudanças.

Um dos precursores dessa ideia, Papert (1994), argumenta que o acesso ao computador pode estabelecer uma relação distinta entre o sujeito e o objeto do conhecimento. $\mathrm{O}$ autor denomina o computador como "máquina do conhecimento", e acredita que a sua inclusão no contexto da Educação é passível de redimensionar as práticas, fomentando um processo educacional ativo e fundamentado no protagonismo do estudante. A proposta do autor baseia-se em inserir a tecnologia digital em articulação com uma proposta pedagógica que supere a transmissão de informações (PAPERT, 1994).

Nesse cenário, apresentam-se múltiplas possibilidades para o professor proporcionar situações em que o estudante desenvolva uma conexão com aquilo que ele vai aprender. $\mathrm{O}$ aluno pode deixar de ser apenas um ouvinte e passar a explorar, manipular e navegar hipertextualmente. Na visão de Lévy, um fluxo hipertextual está relacionado:

A reação ao clique sobre o botão (lugar da tela de onde é possível chamar um outro nó) leva menos de um segundo. A quase instantaneidade da passagem de um nó a outro, permite generalizar e utilizar toda sua extensão o princípio 
da não linearidade. Isto se torna a norma, um novo sistema de escrita, uma metamorfose da leitura, batizada navegação (LÉVY; COSTA, 1993).

Nesse contexto, o sujeito constrói o seu caminho de navegação e de leitura sem um roteiro prévio, a partir de suas construções mentais, tentativas e experiências anteriores.

A utilização de Ambientes Virtuais de Aprendizagem (AVA) também se constitui em uma possibilidade de flexibilização de tempo e de espaço para o desenvolvimento dos processos de ensino e de aprendizagem. Para Costa e Franco (2015), um AVA é algo mais amplo que um site educacional, constituindo-se em um recurso pedagógico digital que pode promover a interatividade e a autonomia do estudante. Para que isso seja possível, a sua constituição deve ser norteada por bases epistemológicas e pedagógicas que possibilitem tais movimentos (COSTA; FRANCO, 2015).

Essas e outras tantas possibilidades não consideradas neste trabalho, em função de limitações de tempo e espaço, podem fornecer ao professor alternativas para redimensionar sua aula. Como contraponto, vale a ressalva feita por Pescador e Flores (2013) de que apenas o recurso tecnológico não é condição suficiente para a mudança, sendo necessário propostas que possibilitem formas distintas de pensar e de agir. Nos parágrafos que seguem, aborda-se esse aspecto, porém direcionado à disciplina de Cálculo diferencial e integral (PESCADOR; FLORES, 2013).

\subsection{As tecnologias digitais e o ensino de Cálculo}

O atual cenário do ensino de Cálculo, marcado por elevados índices de evasão e retenção (FLORES et al., 2017) tem fomentado pesquisas em relação ao tema.

Nesse sentido, Soares e Sauer (2004), argumentam que, de um modo geral, sobretudo cursos de engenharia, tendem a formar profissionais limitados no sentido de articular a Matemática vista na academia com situações pertencentes ao mercado de trabalho e com o cotidiano. As autoras consideram que a visão epistemológica predominante em relação ao ensino ainda se relaciona ao professor como um transmissor da informação e ao estudante como um ouvinte passivo, fato que, para elas, pode explicar os casos de insucesso em relação à disciplina de Cálculo. Mesmo tendo se passado mais de uma década do texto dessas autoras, o quadro, aparentemente, não teve alterações significativas, tendo em vista os cenários descritos por Cabral (2015) e por Flores, Lima e Fontella (2017) que relatam situações similares às descritas por Soares e Sauer (2004) (SOARES; SAUER, 2004) (CABRAL, 2015) (FLORES et al., 2017).

Em busca da reversão desse quadro, são observadas iniciativas, dentre as quais destacamos a inserção de tecnologias digitais, foco deste trabalho. Nesse sentido, Almeida (2013) enfatiza que os recursos tecnológicos digitais se constituem em alternativas para facilitar a visualização, oferecendo um retorno mais rápido em relação às respostas e dinamizando a conjuntura da aula. $\mathrm{O}$ autor também enfatiza as possibilidades de manipulação e representação de conceitos matemáticos com o uso de recursos computacionais (ALMEIDA, 2013). 
Entretanto, o implemento das tecnologias digitais não é condição suficiente para o redimensionamento das ações pedagógicas, pois em muitas ocasiões os recursos tecnológicos digitais acabam se constituindo em um suporte novo para a reprise de velhas práticas (FLORES, 2013). Esse argumento é corroborado por Soares e Sauer (2004) que consideram que tal implantação é executada com a manutenção da visão pedagógica, normalmente pautada pela perspectiva da transmissão de informações, com procedimentos mecânicos e algoritmos padronizados, que parecem não ser suficientes para o desencadear da construção do conhecimento (SOARES; SAUER, 2004).

Na mesma direção, Giraldo, Carvalho e Tall (2003) consideram que o uso de computadores desvinculado de uma proposta pedagógica pode até mesmo dificultar a aprendizagem. Para eles, é indispensável fomentar-se uma concepção de uso, pautada pela criticidade e pela autonomia do estudante, no sentido de analisar e questionar os resultados obtidos pela máquina. Para os autores

O uso inadequado de ambientes computacionais - especialmente se não confrontados com outras formas de representação - pode contribuir para a cristalização da concepção de que as limitações da representação são na verdade características do próprio objeto considerado, levando à formação de imagens conceituais restritas (GIRALDO et al., 2002).

Um exemplo que pode ilustrar a situação referida acima é o gráfico de uma função do segundo grau. Vamos supor que um estudante gere o gráfico em um software, sem conhecer as propriedades da função, com um zoom excessivo na parábola, ele pode concluir equivocadamente que é uma reta (GIRALDO et al., 2002).

Complementando esses argumentos, Soares e Sauer (2004) enfatizam que o estudante, frente a um computador, pode apenas repetir procedimentos sugeridos pelo professor, manipulando um software, o que pode não representar qualquer mudança na sua aprendizagem. Elas sugerem o uso das tecnologias digitais "numa perspectiva em que a ênfase seja a construção do conhecimento realizada pelo aluno" (SOARES; SAUER, 2004). Esse ponto de vista ultrapassa o âmbito da inserção das tecnologias digitais, pressupondo reflexão e redimensionamento das concepções epistemológicas que permeiam as práticas pedagógicas do professor. Quando a inclusão das tecnologias digitais ocorre em consonância com o repensar das práticas, abre-se espaço para o ensino a partir de uma perspectiva crítica com a exploração das habilidades de imaginar, testar e conjecturar.

Menk (2005) relata uma proposta neste sentido, em que um software é utilizado para resolver problemas, cujos conceitos envolvidos são máximos e mínimos de funções. Os envolvidos na pesquisa tiveram a oportunidade de construir hipóteses, confirmando ou refutando-as, em uma proposta que privilegia o pensamento livre e autônomo. $\mathrm{O}$ autor defende que esta concepção de uso da tecnologia digital favorece a análise, a interpretação e a resolução de problemas em Cálculo, aspectos que historicamente constituem-se em entraves para o estudante (MENK, 2005).

Desse modo, parte-se de um pressuposto teórico de que a inserção das tecnologias digitais não é suficiente para o desenvolvimento dos processos de ensino e aprendizagem, sendo 
necessária uma prática pedagógica que leve à autonomia e à postura ativa do estudante enquanto sujeito.

\section{PROCEDIMENTOS UTILIZADOS}

A pesquisa descrita neste artigo foi realizada com uma abordagem qualitativa, do tipo metanálise, de acordo com as concepções teóricas de Bicudo (2014). A realização do trabalho compreendeu um mapeamento da produção nacional relacionada à tecnologia digital e ao ensino de Cálculo, além da organização, análise e interpretação das conclusões alcançadas por distintos pesquisadores, configurando-se em uma compreensão mais ampla (BICUDO, 2014).

Pode-se entender a metanálise como um processo analítico e investigativo no qual, partindo-se de pesquisas que já foram realizadas, é possível o alcance de entendimentos distintos para um fenômeno investigado. Estrutura-se a partir de uma questão norteadora que direciona o processo, passando para localização, seleção e organização dos dados, e culminando com a análise e interpretação, por meio das quais se chega a compreensões inovadoras (BICUDO, 2014). Pressupõe leitura, reflexão, comparação, envolvimento e rigorosidade da parte do pesquisador, o qual deve estar atento aos novos contornos que o entrelaçamento de dados pode oferecer.

Em busca de compreensão para o problema de pesquisa já mencionado, iniciou-se o processo de constituição do corpus de pesquisa, o qual foi composto por artigos publicados em revistas nacionais indexadas pela Capes, com Qualis A1, A2 e B1, nas áreas de Ensino e Educação. Como recorte temporal foi estabelecido o período de 10 anos, ou seja, publicações datadas de 2006 a 2016, a fim de que se pudesse analisar, ainda que implicitamente e não como um dos objetivos iniciais, a maneira que vem se dando o avanço do uso das tecnologias digitais no ensino de Cálculo nesse período. Escolheu-se também analisar apenas pesquisas desenvolvidas no Brasil, uma vez que esse é o local em que se inserem os pesquisadores e suas possíveis pesquisas e ações a serem desenvolvidas após a análise.

O passo inicial foi a localização dos periódicos, que foi feita com uma busca virtual na Plataforma Sucupira ${ }^{4}$, levando em conta a avaliação de 2014. No endereço eletrônico de cada uma das revistas, buscou-se artigos com as seguintes palavras-chave: "Cálculo", "tecnologia", "matemática" e "engenharia". Os artigos selecionados neste processo tiveram seus resumos lidos com o fim de identificar seus enquadramentos nos propósitos da pesquisa. Os textos foram eleitos e organizados em um quadro, considerando-se o problema de pesquisa, os objetivos, os principais resultados e um breve resumo. O processo analítico concentrou-se nos principais resultados. A seguir temos um resumo do quadro referido:

\footnotetext{
${ }^{4}$ Maiores informações em: https://sucupira.capes.gov.br/sucupira/public/consultas/coleta/veiculoPublicacaoQualis/listaConsultaGeralPeriodicos.jsf.
} 


\section{Quadro 1 - Artigos e foco}

\begin{tabular}{|c|c|}
\hline Artigo & Foco do Trabalho \\
\hline $\begin{array}{l}\text { Celular como ferramenta de apoio } \\
\text { pedagógico ao Cálculo }\end{array}$ & $\begin{array}{l}\text { Discutir as possibilidades e limitações do uso do ce- } \\
\text { lular como recurso pedagógico em Cálculo I. }\end{array}$ \\
\hline $\begin{array}{l}\text { Calculadora, computadores e Inter- } \\
\text { net em educação matemática: de- } \\
\text { zoito anos depois }\end{array}$ & $\begin{array}{l}\text { Apresentar as pesquisas de um grupo que, há tempos, } \\
\text { dedica-se à educação matemática, informática e mí- } \\
\text { dias. Em relação à temática, são abordados aspectos } \\
\text { epistemológicos, pedagógicos e formação de profes- } \\
\text { sores. }\end{array}$ \\
\hline $\begin{array}{l}\text { Uma ferramenta de apoio à análise } \\
\text { e ao acompanhamento de práticas } \\
\text { interativas como instrumento meto- } \\
\text { dológico para o ensino de discipli- } \\
\text { nas de matemática }\end{array}$ & $\begin{array}{l}\text { Apresentar uma ferramenta de análise e de acompa- } \\
\text { nhamento associada a um ambiente virtual de apren- } \\
\text { dizagem, com listas de exercícios interativos gerenci- } \\
\text { ados pelo professor. }\end{array}$ \\
\hline $\begin{array}{l}\text { Webquest: uma experiência na dis- } \\
\text { ciplina de Cálculo diferencial e in- } \\
\text { tegral com alunos do curso de quí- } \\
\text { mica }\end{array}$ & $\begin{array}{l}\text { webquest em } \\
\text { ca. }\end{array}$ \\
\hline $\begin{array}{l}\text { Uma sequência didática para explo- } \\
\text { rar a Uma sequência didática para } \\
\text { explorar a regra de L'Hospital com } \\
\text { o uso da tecnologia }\end{array}$ & $\begin{array}{l}\text { Apresentar uma engenharia didática envolvendo si- } \\
\text { tuações de ensino e aprendizagem com a regra de } \\
\text { L'Hospital em um curso de licenciatura em matemá- } \\
\text { tica. }\end{array}$ \\
\hline $\begin{array}{l}\text { Uma investigação sobre o uso de } \\
\text { ferramentas computacionais no en- } \\
\text { sino de Cálculo diferencial e inte- } \\
\text { gral }\end{array}$ & $\begin{array}{l}\text { Descrever uma experiência com o uso de software no } \\
\text { ensino de Cálculo. }\end{array}$ \\
\hline $\begin{array}{l}\text { Atividades investigativas de aplica- } \\
\text { ção de derivadas utilizando o Geo- } \\
\text { gebra. }\end{array}$ & $\begin{array}{l}\text { Apresentar um produto educacional constituído a par- } \\
\text { tir de uma dissertação que aborda aplicações de deri- } \\
\text { vadas com o Geogebra. }\end{array}$ \\
\hline $\begin{array}{l}\text { Professores que usam tecnologia de } \\
\text { informação e comunicação para en- } \\
\text { sinar Cálculo. }\end{array}$ & $\begin{array}{l}\text { Apresentar as compreensões de professores do ensino } \\
\text { superior em relação às tecnologias digitais no ensino } \\
\text { de Cálculo. }\end{array}$ \\
\hline $\begin{array}{l}\text { Integração de tecnologias para } \\
\text { construção de objetos de apren- } \\
\text { dizagem - O case E2D ensino de } \\
\text { derivadas a distância }\end{array}$ & $\begin{array}{l}\text { Apresentar e justificar a construção de um ambiente } \\
\text { para a aprendizagem de derivadas. }\end{array}$ \\
\hline $\begin{array}{l}\text { Trabalhando com os erros dos alu- } \\
\text { nos de Cálculo diferencial e integral } \\
\text { em fóruns do ambiente Moodle }\end{array}$ & $\begin{array}{l}\text { Apresentar uma proposta desenvolvida com alunos, } \\
\text { fundamentada na teoria de David Tall, em que, no fó- } \\
\text { rum do Moodle, são discutidas as dificuldades na dis- } \\
\text { ciplina. }\end{array}$ \\
\hline Caiu na net e agora? & $\begin{array}{l}\text { Problematizar a lógica dos textos de Cálculo que se- } \\
\text { guem uma lógica linear, contrapondo os movimentos } \\
\text { contemporâneos hipertextuais de leitura. }\end{array}$ \\
\hline
\end{tabular}

Fonte: Elaborado pelos autores.

Findadas as etapas de coleta e organização, iniciou-se a análise, que seguiu a perspectiva teórica da Análise Textual Discursiva (ATD), de acordo com os pressupostos de Moraes e Galiazzi (2007). A ATD é um movimento cíclico e reconstrutivo que visa identificar a construção de 
compreensões de discursos a partir de três ciclos não lineares: a unitarização, a categorização e a comunicação do novo emergente (MORAES; GALIAZZI, 2007). O ciclo da unitarização teve início com uma leitura criteriosa dos trabalhos selecionados, com um olhar para o seu foco, objetivos e problema de pesquisa. $\mathrm{O}$ intuito foi a desconstrução dos textos em busca de unidades de significado, interpretando cada fragmento, que foi separado e classificado com um palavrachave de acordo com o seu sentido. Na sequência, essas palavras-chave foram consideradas categorias e agrupadas segundo a sua semelhança, o que constitui o segundo ciclo: a categorização. A reescrita das categorias e sua articulação com a teoria constituíram a comunicação, apresentada na próxima seção (MORAES; GALIAZZI, 2007).

\section{APRESENTAÇÃO E ANÁLISE DE DADOS}

A partir da análise dos artigos selecionados, chegou-se a três categorias, denominadas: (i) recursos de apoio, (ii) software e (iii) ensino e tecnologia. Foram considerados recursos de apoio as tecnologias móveis, destacando os smartphones, os tablets e as calculadoras. Mesmo que um software também seja um recurso de apoio, eles foram enquadrados em uma categoria separada, contemplando programas específicos para computadores. Já ensino e tecnologia é uma categoria que foca mais essencialmente nas práticas pedagógicas apoiadas por algum recurso tecnológico digital.

\subsection{Recursos de apoio}

Observamos alguns trabalhos que enfatizam os recursos de apoio como possibilidades para qualificar as aulas de Cálculo. Em um dos artigos, Maltempi, Javaroni e Carvalho (2011) apresentam um relato de experiências bem-sucedidas nesse sentido. Os autores consideram que não basta o implemento da tecnologia, sendo necessária uma reflexão epistemológica e pedagógica que adentre na formação de professores. Mesmo as tecnologias sendo entendidas como agentes que podem reconfigurar as práticas, alguns estudos indicam possíveis limitações (MALTEMPI et al., 2011).

Em outro trabalho, Batista et al. (2011) enfatizam que, dependendo do recurso, faz-se necessário um período de adaptação, envolvendo, por exemplo, o download antes da utilização. Aparelhos com limitação tecnológica também podem prejudicar ou mesmo inviabilizar as propostas que dependam de um programa específico, uma vez que determinados aplicativos funcionam em alguns sistemas operacionais e não em outros. Essas observações sinalizam para a necessidade da atenção que o professor deve ter quando utilizar as tecnologias digitais, desenvolvendo propostas que não excluam aqueles que não possuam o acesso aos recursos necessários às atividades (BATISTA et al., 2011).

Outro recurso identificado foi o webquest, entendido como uma proposta orientada, pau- 
tada pela interação, cujas informações utilizadas são oriundas da Internet. Uma proposta nesse sentido foi relatada por Passos e Broietti (2010), em que o objetivo consistiu em pesquisar o desenvolvimento do conceito de derivada e de suas aplicações. Durante o trabalho, fez-se uma sondagem escrita das impressões dos estudantes sobre a tarefa proposta. Para eles, a produção de texto nas aulas de matemática foi uma atividade diferenciada, algo que ainda não tinham vivenciado. Passos e Broietti (2010) também indicaram a importância de conhecer o desenvolvimento histórico do conceito de derivada, relatando certa facilidade de sua aplicação, sobretudo na química, a partir da experiência realizada. Compreender a aplicabilidade dos conceitos, segundo Soares e Sauer (2004), é considerado um ponto crucial para a aprendizagem de Cálculo (PASSOS; BROIETTI, 2010) (SOARES; SAUER, 2004).

Em outro artigo analisado (PEQUENO et al., 2012), destacou-se um recurso de acompanhamento e de análise de realização de tarefas que tinha o fim de mapear a evolução e as dificuldades dos estudantes. Associado ao ambiente virtual de aprendizagem da turma, o professor disponibiliza listas de exercícios, identificando, avaliando e realimentando-as continuamente. Os resultados preliminares indicam que a proposta permite ao professor realizar intervenções no decorrer do semestre, podendo reverter eventuais dificuldades e redimensionar a sua prática no sentido de adaptar a sua aula ao nível de conhecimento dos discentes. A proposta parece ultrapassar a simples disponibilização de exercícios de forma digital, ação que apenas mudaria o suporte, que é questionada por Soares e Sauer (2004) e que adentra na perspectiva de mudanças nas práticas a partir das percepções possibilitadas pelos recursos (SOARES; SAUER, 2004).

Em outro trabalho, Amaral e Müller (2012) apresentam um projeto que integra distintos recursos tecnológicos a fim de construir objetos de aprendizagem para o estudo de derivadas. Tal projeto está fundamentado em pesquisas que comprovam a histórica dificuldade dos estudantes na disciplina de Cálculo e em autores, principalmente das áreas de matemática e informática na educação, que justificam o seu potencial para a promoção da aprendizagem. Nesse estudo, é apresentada apenas a construção do ambiente, o qual ainda não havia sido utilizado com estudantes (AMARAL; MÜLLER, 2012).

\subsection{Software}

Durante o processo de análise identificou-se que distintas pesquisas apontam para o uso de software como alternativa para a qualificação dos processos de ensino e aprendizagem. Destaca-se que os estudos considerados indicam, de maneira especial, as possibilidades de manipulação e representação oferecidas por esses recursos digitais, mas também as práticas pedagógicas que possibilitam um olhar distinto para o objeto de aprendizagem.

Inicialmente, destacamos que alguns estudos indicaram que determinados software podem auxiliar na articulação entre as abordagens geométrica e analítico-algébrica do Cálculo. Em uma das pesquisas consideradas neste trabalho, realizada por Alves e Neto (2012), foram indicadas possibilidades de comparação entre os aspectos algébricos e analíticos. Na visão dos 
autores, esse tipo de prática tende a se tornar ainda mais exequível em um contexto em que os recursos tecnológicos digitais estão envolvidos. Na investigação apresentada, o dinamismo oferecido pelo programa utilizado levou a um melhor entendimento de distintos conceitos, além de fomentar o senso de investigação e de pesquisa no grupo envolvido. Argumentos similares são encontrados em Gonçalves e Reis (2013), que consideram o uso de software como um fator passível de promover um contexto distinto para a aprendizagem, pautado por interações e por movimentos que levam ao refletir e ao repensar. A proposta levou os estudantes a ressignificar conceitos relevantes para a aprendizagem de Cálculo, além de criar um ambiente de aprendizagem diferente, ampliando e complementando as ações desenvolvidas em sala de aula. Esse mesmo estudo também indicou que a inclusão planejada das tecnologias digitais na Educação leva a movimentos para a formação de "um novo professor", articulado com o contexto da sociedade contemporânea (ALVES; NETO, 2012) (GONÇALVES; REIS, 2013).

Em contraponto, um dos estudos (PAULA et al., 2015) demonstrou que muitos professores ainda oferecem resistência em relação a redimensionar práticas já conhecidas e testar metodologias alternativas para a aula. Nessa investigação, uma parcela dos entrevistados mencionou acreditar na mudança que as tecnologias podem oferecer à Educação, mas o estudo conclui que isto ainda não está consolidado em suas práticas. Esses argumentos parecem confirmar as sugestões de Pescador e Flores (2013), que preconizam o implemento das tecnologias digitais em consonância com a formação dos professores. Essa formação não deve visar apenas o treinamento para a utilização das tecnologias, mas desenvolver, a partir do debate e da reflexão, concepções de uso que superem a transmissão de informações e gerem movimentos interativos na aula. Esse parece ser um ponto crucial: os reflexos que as tecnologias digitais produzem nas práticas (PESCADOR; FLORES, 2013).

\subsection{Ensino e tecnologia}

O modo de ensinar no contexto das tecnologias digitais foi uma pauta comum em distintos artigos analisados. Percebem-se muitos movimentos no sentido de redimensionar as ações pedagógicas a partir da inclusão da tecnologia digital, processos que parecem ainda não estar totalmente consolidados.

Marin e Penteado (2011) indicam o desejo dos professores de incluir e adequar as suas aulas ao contexto das tecnologias digitais. No entanto, isso não se reflete nas práticas, que tendem a permanecer sem alterações, muito em função de entraves tais como as necessidades de formação e de planejamento. A aposta nas tecnologias digitais parece ainda estar mais no plano do discurso do que no da ação. A perspectiva indicada vai ao encontro das sinalizações de Pescador e Flores (2013), os quais problematizam a inserção vertical das tecnologias digitais, que, em muitos casos, ocorre sem reflexão ou mudança nos cenários pedagógicos (MARIN; PENTEADO, 2011) (PESCADOR; FLORES, 2013).

Já Mendes e Maltempi (2015) questionam a disposição hierárquica dos conteúdos de 
Cálculo, a qual seria quase uma antítese do formato hipertextual em que as informações se organizam na web. Os autores argumentam que, enquanto na Internet navegamos cruzando dados, sem um roteiro definido, no ensino de Cálculo, temos uma sequência linear, com limites, continuidade, derivadas, integrais. Eles consideram que essa linearidade contrapõe os movimentos cognitivos do sujeito contemporâneo, sendo possível superar esse modelo a partir de discussões e práticas baseadas em problemas, fomentando uma aprendizagem sistêmica. Soares e Sauer (2004) já indicam essa perspectiva há mais de uma década, considerando que o ensino de Cálculo deve buscar mobilização dos saberes e ressignificação dos conteúdos a partir de fluxos constantes de reconstrução, por meios de reflexões e transformações. Isso pressupõe o entendimento do estudante como um sujeito autônomo e ativo no processo (MENDES; MALTEMPI, 2015) (SOARES; SAUER, 2004).

Em outro artigo analisado (MÜLLER et al., 2015), os autores analisam os fóruns de um AVA de uma disciplina, com o fim de identificar os erros dos estudantes. Eles concluem que o conteúdo de inequações concentrou uma parcela significativa dos equívocos. Para a solução desses problemas, no decorrer do semestre, o fórum teve um papel muito relevante, uma vez que possibilitou um nível profundo de discussões e interações entre as partes. Eles sinalizam melhoras na aprendizagem e no rendimento dos discentes, atribuídas ao uso do recurso tecnológico digital, especialmente o fórum. Essa perspectiva converge com os pressupostos de Costa e Franco (2015), em que o AVA é utilizado em uma perspectiva interativa, fomentando a aprendizagem a partir das relações estabelecidas. Esse nível de utilização supera a simples inserção das tecnologias digitais, adentrando na esfera de adequar a prática docente em consonância com os recursos (COSTA; FRANCO, 2015).

\section{CONSIDERAÇÕES FINAIS}

Os recursos tecnológicos digitais podem fornecer possibilidades distintas de visualização e de manipulação de conceitos, facilitando o trânsito entre as abordagens analítica e geométrica. Entretanto, a simples inserção desses recursos não é o suficiente para reconfigurar as práticas educativas, sendo necessárias ações que entendam o estudante como um sujeito autônomo e ativo no processo de aprendizagem. Isso pressupõe a criação de situações em que os pares possam interagir, trocar ideias e argumentar, o que pode ser flexibilizado em função das possibilidades de estender as dimensões de tempo e de espaço fornecidas pelas tecnologias digitais.

Tornar alguns aspectos das aulas de Cálculo menos rígidos é outra possibilidade percebida neste trabalho. Ampliar a comunicação, possibilitar o estudo e a realização de tarefas com acompanhamento dinâmico fora da sala de aula pode desencadear um melhor aproveitamento do tempo, muitas vezes escasso em função dos programas e das exigências das Instituições de Ensino Superior. Isso sugere que a educação a distância também pode aproveitar os distintos recursos tecnológicos digitais, ampliando o alcance do ensino. 
Em relação ao avanço do uso das tecnologias digitais no ensino de Cálculo no período considerado, percebemos alguns movimentos na direção do seu implemento nas aulas. Percebemos que alguns software, em especial o Geogebra, já são utilizados como uma possibilidade de representar os conceitos de outras maneiras. Recursos como, por exemplo, celulares, já são percebidos como algo passível de auxiliar o professor no desenvolvimento dos processos de ensino e aprendizagem.

Por último, considera-se que muito já foi feito em relação à inclusão das tecnologias digitais. Distintos trabalhos indicam que é possível promover alterações no desenvolvimento dos processos de ensino e de aprendizagem. Entretanto, é claramente reconhecido que ainda é preciso avançar muito, principalmente no sentido de fomentar concepções de uso em que preponderam a criatividade, o senso crítico e os movimentos interativos entre os pares. 


\section{REFERÊNCIAS}

ALMEIDA, H. R. F. L. O uso das tecnologias digitais da informação e comunicação na aula de cálculo 1 a distância. In: XVII Encontro Brasileiro de Estudantes de Pós-Graduação em Educação Matemática. Vitória, ES: [s.n.], 2013.

ALVES, F. R.; NETO, H. B. Uma sequência didática para explorar a regra de l'hospital com o uso da tecnologia. Educação Matemática Pesquisa, v. 14, n. 2, 2012.

AMARAL, E. M. H.; MÜLLER, T. J. Integração de tecnologias para construção de objetos de aprendizagem-o case e2d ensino de derivadas a distância. RENOTE, v. 10, n. 1, 2012.

BATISTA, S. C. F. et al. Celular como ferramenta de apoio pedagógico ao cálculo. RENOTE, v. 9, n. 1, 2011.

BICUDO, M. A. V. Meta-análise: seu significado para a pesquisa qualitativa. Revemat: revista eletrônica de educação matemática, v. 9, p. 7-20, 2014.

CABRAL, T. C. B. Metodologias alternativas e suas vicissitudes: ensino de matemática para engenharias. Perspectivas da Educação Matemática, v. 8, n. 17, 2015.

COSTA, L. A. C.; FRANCO, S. R. K. Ambientes virtuais de aprendizagem e suas possibilidades construtivas. RENOTE, v. 13, n. 2, 2015.

FLORES, J.B. Ler e escrever matemática: Desafios para o ensino de matemática na modalidade a distância. Revista Eletrônica de Educação, v. 7, n. 1, p. 383-394, 2013.

FLORES, J. B.; LIMA, V. M. R.; FONTELLA, C. R. Análise das monitorias de cálculo e de física: um estudo de caso em cursos de engenharia. Caderno Brasileiro de Ensino de Física, Universidade Federal de Santa Catarina (UFSC), v. 34, n. 1, p. 47-63, 2017.

GIRALDO, V.; CARVALHO, L. M.; TALL, D. Conflitos teórico-computacionais e a imagem conceitual de derivada. LM Carvalho and LC Guimarães, IHTEM, v. 1, p. 153-164, 2002.

GONÇALVES, D. C.; REIS, F. S. Atividades investigativas de aplicações das derivadas utilizando o geogebra. Boletim de Educação Matemática, Universidade Estadual Paulista Júlio de Mesquita Filho, v. 27, n. 46, 2013.

LEMOS, A. Cibercultura, tecnologia e vida social na cultura contemporânea. Porto Alegre: Sulina, 2002.

LÉVY, Pierre; COSTA, Carlos Irineu da. tecnologias da inteligência, As. Rio de Janeiro: Editora $34,1993$.

MALTEMPI, M. V.; JAVARONI, S. L.; CARVALHO, B. M. Calculadoras, computadores e internet em educação matemática: dezoito anos de pesquisa. Boletim de Educação Matemática, Universidade Estadual Paulista Júlio de Mesquita Filho, v. 25, n. 41, p. 43-72, 2011.

MARIN, D.; PENTEADO, M. G. Professores que utilizam tecnologia de informação e comunicação para ensinar cálculo. Educação Matemática Pesquisa, Pontificia Universidade Catolica de Sao Paulo PUC-SP, Programa de Estudos Pós-Graduados em Educação Matemática, v. 13, n. 3, p. 527, 2011. 
MENDES, R. O.; MALTEMPI, M. V. Caiu na net: e agora?/it's on the web: what now? Bolema, Universidade Estadual Paulista"Julio de Mesquita Filho-IGCE-Depto de Matemática, v. 29, n. 53, p. 1066, 2015.

MENK, L. F. F. Contribuições de um software de geometria dinâmica na exploração de problemas de máximos e mínimos. 2005. Dissertação (Mestrado) - Universidade Estadual de Londrina, Londrina, PR.

MORAES, R.; GALIAZZI, M. C. Análise textual: discursiva. Ijuí: Editora Unijuí, 2007.

MÜLlER, T. J. Objetos de Aprendizagem Multimodais e Ensino de Cálculo: uma proposta baseada em análise de erros. 2015. Tese (Doutorado) — UFRGS, tese do doutorado em Informática na Educação.

MÜLLER, T. J.; LIMA, J. V.; CURY, H. N. Trabalhando com os erros de alunos de cálculo diferencial e integral em fóruns do ambiente moodle. RENOTE, v. 13, n. 2, 2015.

OLIVEIRA, M. C. A.; RAAD, M. R. A existência de uma cultura escolar de reprovação no ensino de cálculo. Boletim GEPEM, v. 61, p. 125-137, jun./dez. 2012.

PAPERT, S. A máquina das crianças: repensando a escola na era digital. Porto Alegre: Artes Médicas, 1994.

PASSOS, A.Q.; BROIETTI, F.C.D. Webquest: Uma experiência na disciplina de cálculo diferencial e integral com alunos do curso de química. Experiências em Ensino de Ciências, v. 5, n. 1, p. 159-168, 2010.

PAULA, S. C. R. et al. Uma investigação sobre o uso de ferramentas computacionais no ensino de cálculo integral e diferencial. RENOTE, v. 13, n. 2, 2015.

PEQUENO, P. A. L. et al. Uma ferramenta de apoio à análise e ao acompanhamento de práticas interativas como instrumento metodológico para o ensino de disciplinas de matemática. RENOTE, v. 10, n. 3, 2012.

PESCADOR, C. M.; FLORES, J. B. O laptop educacional na escola: uma reflexão sobre inclusão digital. RENOTE, v. 11, n. 1, 2013.

SOARES, E. M. S.; SAUER, L. Z. Um novo olhar sobre a aprendizagem de matemática para a engenharia. Disciplinas matemáticas em cursos superiores.(Cury, HN ed), p. 245-270, 2004. 